\title{
Impact of socioeconomic status in patients hospitalised for COVID-19 in the Greater Paris area
}

To the Editor:

In the USA, coronavirus disease 2019 (COVID-19) is more likely to affect and kill African Americans [1], which raises the question of the contribution of several factors, including genetic background, socioeconomic status (SES), and comorbidities [2]. According to the French National Institute of Statistics and Economic Studies (INSEE) the highest excess mortality rate in France, during March and April 2020, linked to COVID-19 was found in the Seine-Saint-Denis (SSD) district [3]. SSD is the poorest district of Greater Paris [4]. We hypothesise that precarity influences the initial severity of COVID-19.

We selected patients hospitalised for COVID-19 at Avicenne Academic Hospital, in SSD and at Beaujon and Ambroise Paré Hospitals, two academic hospitals located in the Hauts-de-Seine (HDS) district. HDS is a wealthy district of Greater Paris, with more hospital beds (56.7 versus 42.5 per 10000 inhabitants) and intensive care unit (ICU) beds (429 versus 244) than SSD for an equivalent number of inhabitants (1.6 million) $[5,6]$. The goal was to compare patient characteristics between the two districts and determine whether precarity is a risk factor for severe COVID-19. All consecutive conscious patients hospitalised in the three hospitals for COVID-19 were prospectively screened on the same day (20 April 2020). Patients were asked about their SES via a questionnaire (monthly personal self-reported income, deprivation index, insurance coverage, occupation, final educational degree and housing conditions), and information on smoking habits, comorbidities and respiratory severity at admission was collected. The French deprivation index EPICES (Evaluation of Health Inequalities for Health Insurance Health Examination Centre) is an indicator of precarity taking into account marital status, insurance coverage, family support and leisure activity. The score varies from 0 (absence of precarity) to 100 (maximum precarity). 30 is considered to be the precarity threshold [7]. The official French poverty line corresponds to a monthly income of less than EUR 1041. Initial severity was classified as follows: no severity (oxygen requirements $<3 \mathrm{~L} \cdot \mathrm{min}^{-1}$ ), moderate severity (oxygen requirements between 3 and $5 \mathrm{~L} \cdot \mathrm{min}^{-1}$ ), significant severity (respiratory rate $>30 \mathrm{~min}^{-1}$, or oxygen requirements $>5 \mathrm{~L} \cdot \mathrm{min}^{-1}$, or lung damage on computed tomography scan $>50 \%$ ), and critical severity (admission to intensive care) $[8,9]$. Results are expressed as percentages or mean $\pm \mathrm{SD}$. Logistic regression was used to identify the factors associated with severe COVID-19 at admission. All patients signed a consent form and the study was approved by the local ethics committee (CLEA-2020-116).

190 patients hospitalised for COVID-19 were screened, and $41 \%$ of these were excluded (for cognitive disorders: $45 \%$; language barrier: $21 \%$; critical state: 15\%; tutorship or curatorship: $11 \%$; and lack of consent: $8 \%$ ). The causes of exclusion differed according to the district, with higher language barrier in SSD but more lack of consent or cognitive disorders in HSD ( $\mathrm{p}=0.02)$. Excluded patients were significantly older than included patients $(74.5 \pm 15.8$ versus $66.6 \pm 16.3$ years; $\mathrm{p}<0.001)$, with a higher proportion of patients over 70 years old $(66 \%$ versus $41 \%$; $<0.001)$. The study population included 112 patients (65 (58.6\%) males, age 66.7 \pm 16.3 years, 12 (11.0\%) Africans or Afro-Caribbeans, and eight (7.7\%) current smokers). Body mass index was $27.1 \pm 6.23,33$ (30.0\%) patients had diabetes and $58(52.7 \%)$ arterial hypertension. Regarding SES, 32 (33.0\%) patients had an income below the poverty line, and the mean deprivation index was $38.2 \pm 24.4$. The proportion of patients with at least one infected home co-resident was $12 \%$. COVID-19 was severe in most cases (59.8\%).

@ERSpublications

Individual precarity seems to be associated with the initial severity of COVID-19 in hospitalised patients under the age of $\mathbf{7 0}$ years. Low socioeconomic status may contribute to the excess mortality observed in the poorest district of Greater Paris. https://bit.ly/3kuStXS

Cite this article as: Sesé L, Nguyen Y, Giroux Leprieur E, et al. Impact of socioeconomic status in patients hospitalised for COVID-19 in the Greater Paris area. Eur Respir J 2020; 56: 2002364 [https://doi.org/ 10.1183/13993003.02364-2020]. 
Patient characteristics are described in table 1. SSD patients were younger $(p=0.002)$ and had more comorbidities, such as being overweight $(p<0.001)$ and diabetes $(p=0.041)$, than HDS patients. The SES of SSD patients was lower, with lower incomes $(p=0.004)$, less private insurance coverage $(p=0.043)$, and a lower educational level $(\mathrm{p}=0.002)$. The proportion of SSD patients who owned homes was lower $(\mathrm{p}=0.039)$ while the proportion of those in low-income housing, and housing population density, was higher ( $\mathrm{p}=0.009$ and $\mathrm{p}=0.027$, respectively). The distribution of initial severity was similar in both districts, although SSD patients were about 10 years younger than HDS patients $(61.8 \pm 14.0$ versus $71.0 \pm 17.1$ years; $\mathrm{p}=0.002) .17$ patients $(17 \%)$ were transferred to the ICU and three patients $(3 \%)$ died at hospital.

\begin{tabular}{|c|c|c|c|c|}
\hline & All & Hauts de Seine & Seine-Saint-Denis & p-value \\
\hline Subjects & 112 & 60 & 52 & \\
\hline Age years & $66.7 \pm 16.3$ & $71.0 \pm 17.1$ & $61.8 \pm 14.0$ & 0.002 \\
\hline Age $<70$ years & $65(58.6 \%)$ & $27(45.8 \%)$ & $38(73.1 \%)$ & 0.006 \\
\hline Males & $65(58.6 \%)$ & $40(66.7 \%)$ & $25(49.0 \%)$ & 0.065 \\
\hline Of African or Afro-Caribbean origin & $12(11.0 \%)$ & $9(15.0 \%)$ & $3(6.1 \%)$ & 0.244 \\
\hline Smokers & & & & 0.746 \\
\hline Never & $59(56.7 \%)$ & $32(53.3 \%)$ & $27(61.4 \%)$ & \\
\hline Former & $37(35.6 \%)$ & $23(38.3 \%)$ & $14(31.8 \%)$ & \\
\hline Current & $8(7.7 \%)$ & $5(8.3 \%)$ & $3(6.8 \%)$ & \\
\hline BMI & $27.1 \pm 6.23$ & $25.2 \pm 5.67$ & $29.6 \pm 6.08$ & $<0.001$ \\
\hline Diabetes & $33(30.0 \%)$ & $13(21.7 \%)$ & $20(40.0 \%)$ & 0.041 \\
\hline Arterial hypertension & $58(52.7 \%)$ & $31(51.7 \%)$ & $27(54.0 \%)$ & 0.958 \\
\hline \multicolumn{5}{|l|}{ Socioeconomic status } \\
\hline Under poverty line ${ }^{\#}$ & $32(33.0 \%)$ & $12(24.5 \%)$ & $20(41.7 \%)$ & 0.078 \\
\hline Monthly income range & & & & 0.004 \\
\hline EUR $400-800$ & $26(28.6 \%)$ & $9(19.6 \%)$ & $17(37.8 \%)$ & \\
\hline EUR 800-1200 & $20(22.0 \%)$ & $8(17.4 \%)$ & $12(26.7 \%)$ & \\
\hline EUR 1200-2500 & $25(27.5 \%)$ & $12(26.1 \%)$ & $13(28.9 \%)$ & \\
\hline EUR $>2500$ & $20(22.0 \%)$ & $17(37.0 \%)$ & $3(6.67 \%)$ & \\
\hline EPICES score ${ }^{\pi}$ & $38.2 \pm 24.4$ & $39.1 \pm 25.5$ & $37.3 \pm 23.3$ & 0.707 \\
\hline High school graduate & $42(40.8 \%)$ & $30(56.6 \%)$ & $12(24.0 \%)$ & 0.002 \\
\hline Retired & $64(57.7 \%)$ & $36(61.0 \%)$ & $28(53.8 \%)$ & 0.568 \\
\hline State health insurance & $108(97.3 \%)$ & $58(98.3 \%)$ & $50(96.2 \%)$ & 0.599 \\
\hline Private health insurance & $73(66.4 \%)$ & $44(75.9 \%)$ & $29(55.8 \%)$ & 0.043 \\
\hline \multicolumn{5}{|l|}{ Housing } \\
\hline Owner & $44(40.0 \%)$ & $29(50.0 \%)$ & $15(28.8 \%)$ & 0.039 \\
\hline Social housing tenant & $48(43.6 \%)$ & $18(31.0 \%)$ & $30(57.7 \%)$ & 0.009 \\
\hline Number of co-residents & $1.75 \pm 1.6$ & $1.67 \pm 1.6$ & $1.85 \pm 1.5$ & 0.557 \\
\hline Housing population density ${ }^{+}$ & $31.0 \pm 33.7$ & $37.3 \pm 40.4$ & $23.7 \pm 22.1$ & 0.027 \\
\hline Infected co-residents & $11(12.0 \%)$ & $2(4.88 \%)$ & $9(17.6 \%)$ & 0.068 \\
\hline Initial severity ${ }^{\S}$ & & & & 0.821 \\
\hline 0 & $44(39.6 \%)$ & $23(38.3 \%)$ & $21(41.2 \%)$ & \\
\hline 1 & $39(35.1 \%)$ & $21(35.0 \%)$ & $18(35.3 \%)$ & \\
\hline 2 & $25(22.5 \%)$ & $15(25.0 \%)$ & $10(19.6 \%)$ & \\
\hline 3 & $3(2.70 \%)$ & $1(1.67 \%)$ & $2(3.92 \%)$ & \\
\hline \multicolumn{5}{|l|}{ Outcomes } \\
\hline Admission to the intensive care unit & $17(16 \%)$ & $12(21 \%)$ & $5(10 \%)$ & 0.195 \\
\hline Death & $3(3 \%)$ & $2(2 \%)$ & $1(1 \%)$ & \\
\hline
\end{tabular}

Data are presented as $\mathrm{n}, \mathrm{n}(\%)$ or mean \pm SD, unless otherwise stated. ${ }^{\#}$ : the poverty line in France is defined by a monthly income lower than EUR 1041 per person, according to INSEE (National Institute for Statistics and Economic Studies) in 2017. ": the EPICES score (Evaluation of Health Inequalities for Health Insurance Examination Centres) is an individual deprivation index that takes into account the multidimensional nature of precariousness. The score is continuous and varies from 0 labsence of precarity) to 100 (maximum precarity). The threshold of 30 is considered as the precariousness threshold. ${ }^{+}$: housing population density was measured by the area of the household $\left(\mathrm{m}^{2}\right)$ divided by the number of residents. ${ }^{\S}$ : initial severity: 0 : not severe loxygen requirements $<3 \mathrm{~L} \cdot \mathrm{min}^{-1}$ ); 1 : moderate severity (oxygen requirements between 3 and $5 \mathrm{~L} \cdot \mathrm{min}^{-1}$ ); 2: significant severity (respiratory rate $>30 \mathrm{~min}^{-1}$, oxygen requirements $>5 \mathrm{~L} \cdot \mathrm{min}^{-1}$ or lung damage on computed tomography scan $>50 \%$ ); 3 : critical severity (admission to intensive care). BMI: body mass index. 
No predictive factors of initial severity were found in the overall population. In the subgroup of patients under 70 years of age $(n=62)$, the predictive factors of severity were age $(p=0.002)$, high EPICES score $(\mathrm{p}=0.014)$, being retired $(\mathrm{p}=0.027)$, and an absence of private insurance coverage $(\mathrm{p}=0.042)$. On multivariate analysis, age and EPICES score were independently associated to an increased risk of initial severity, with an odds ratio of 1.099 (95\% CI 1.038-1.178; p=0.003), and 1.029 (95\% CI 1.003-1.059; $\mathrm{p}=0.033)$ per EPICES score point, respectively.

This is the first study to show that precarity is associated with the initial severity of COVID-19 in hospitalised patients under 70 years old. Moreover, patients hospitalised in SSD, the poorest district in Greater Paris, were 10 years younger than patients hospitalised in the HDS district for the same distribution of initial severity.

First, these results confirmed the precarious conditions of patients hospitalised for COVID-19, even in HDS. Indeed, $24.5 \%$ of the cases were living below the poverty line, while this concerns only $12 \%$ of the inhabitants of HDS district [4]. As expected, SSD patients were younger, which probably reflects the demographic structure of the district, with the youngest population in the region. Although age has been shown to be strongly associated with COVID-19 morbi-mortality [10], the young age of SSD patients does not seem to protect them from severe forms of the disease. This could be explained by the increased prevalence of obesity and diabetes in this group, two comorbidities known to be associated with the severity of COVID-19 [11, 12]. Furthermore, patients hospitalised in SSD had substantially lower incomes, a major indicator of life expectancy in literature [13]. These patients also had a lower level of education, a recognised source of health inequalities $[14,15]$. Finally, housing conditions differed between the two districts, including more social housing and greater promiscuity in SSD patients, with a trend towards more infected home co-residents. Poor housing conditions could have been a barrier to social distancing.

Noticeably, the EPICES score did not differ between the two districts, and it was not identified as a risk factor for disease severity in the overall population. The EPICES score is strongly correlated to the Townsend index [16]. It is generated as the sum of 11 items, including leisure activity. However, this score, which was validated in a $45.5 \pm 14.3$-year-old cohort [7], may not be suitable for geriatric populations. Indeed, among the elderly, not having leisure activities may be more strongly related to dependency than to precarity. Thus, we focused on the subgroup of patients under the age of 70 years, in whom a high EPICES score was found to be a significant risk factor for severe COVID-19.

To our knowledge this is the first study to evaluate individual SES in patients hospitalised for COVID-19. However, it is limited by the high exclusion rate. Although this may have created a selection bias, it shows the complexity of this type of investigation in the acute phase of COVID-19. Moreover, the analysis of factors associated with poor survival was limited by the small number of events.

In conclusion, precarity seems to be associated with the initial severity of COVID-19 in hospitalised patients under 70 years of age. In addition to a lack of hospital beds and ICU beds, low SES may contribute to the excess mortality observed in SSD. Particular attention should be paid to more disadvantaged geographic areas to fight against health disparities in the context of the COVID-19 epidemic.

Lucile Sesé ${ }^{1}$, Yann Nguyen ${ }^{2}$, Etienne Giroux Leprieur ${ }^{3}$, Isabella Annesi-Maesano ${ }^{4}$, Catherine Cavalin ${ }^{5}$, Jeanne Goupil de Bouillé ${ }^{6}$, Louis Demestier ${ }^{7}$, Robin Dhote ${ }^{8}$, Yacine Tandjaoui-Lambiotte ${ }^{9}$, Adeline Bauvois ${ }^{10}$, Marion Pépin ${ }^{11}$, Sonja Curac ${ }^{12}$, Sébastien Beaune ${ }^{13}$, Boris Duchemann ${ }^{14,16}$ and Hilario Nunes ${ }^{15,16}$

${ }^{1}$ Dept of Physiology and Pulmonology, Avicenne Hospital, Assistance Publique-Hôpitaux de Paris, Sorbonne University of Paris Nord, Bobigny, France. ${ }^{2}$ Dept of Internal Medicine, Beaujon Hospital, Assistance Publique-Hôpitaux de Paris, University of Paris, Clichy, France. ${ }^{3}$ Dept of Pulmonology and Thoracic Oncology, Ambroise Paré Hospital, Assistance Publique-Hôpitaux de Paris, Paris-Saclay University UVSQ, EA 4340 BECCOH, Boulogne, France. ${ }^{4}$ Epidemiology of Allergic and Respiratory Diseases Dept, Institute Pierre Louis of Epidemiology and Public Health, INSERM, and UPMC Sorbonne Université, Medical School Saint Antoine, Paris, France. ${ }^{5}$ Social Science Research Institute (IRISSO, UMR CNRS-INRA 7170-1427), Paris-Dauphine University, PSL, Paris, France. ${ }^{6}$ Dept of Infectious Diseases, Avicenne Hospital, Assistance Publique-Hôpitaux de Paris, Sorbonne University of Paris Nord, Bobigny, France. ${ }^{7}$ Dept of Gastroenterology and Pancreatology, Beaujon Hospital, Assistance Publique-Hôpitaux de Paris, University of Paris, Clichy, France. ${ }^{8}$ Dept of Internal Medicine, Avicenne Hospital, Assistance Publique-Hôpitaux de Paris, Sorbonne University of Paris Nord, Bobigny, France. ${ }^{9}$ Dept of Reanimation, Avicenne Hospital, Assistance Publique-Hôpitaux de Paris, Sorbonne University of Paris Nord, Bobigny, France. ${ }^{10}$ Dept of Infectious Diseases, Ambroise Paré Hospital, Assistance Publique-Hôpitaux de Paris, Paris-Saclay University UVSQ, EA 4340 BECCOH, Boulogne, France. ${ }^{11}$ Dept of Geriatrics, Ambroise Paré Hospital, Assistance Publique-Hôpitaux de Paris, Paris-Saclay University UVSQ, EA 4340 BECCOH, Boulogne, France. ${ }^{12}$ Emergency Dept, Beaujon Hospital, Assistance Publique-Hôpitaux de Paris, University of Paris, Clichy, France. ${ }^{13}$ Emergency Dept, Ambroise Paré Hospital, Assistance Publique-Hôpitaux de Paris, ParisSaclay University UVSQ, EA $4340 \mathrm{BECCOH}$, Boulogne, France. ${ }^{14}$ Dept of Oncology, Avicenne Hospital, Assistance Publique-Hôpitaux de Paris, Sorbonne University of Paris Nord, Bobigny, France. ${ }^{15}$ Dept of Pulmonology, Avicenne Hospital, Assistance Publique-Hôpitaux de Paris, Sorbonne University of Paris Nord, INSERM1272, Bobigny, France. ${ }^{16}$ Both authors contributed equally. 
Correspondence: Lucile Sesé, Service de Pneumologie, Hôpital Avicenne, 125 rue de Stalingrad, 93009 Bobigny, France. E-mail: lucile.sese@aphp.fr

Received: 17 June 2020 | Accepted after revision: 16 Oct 2020

Data sharing: The data are available on request.

Acknowledgements: A. Aigron, D. Bouvry, S. Chauveau, A. Claveirole, T. Chinet, A. Costantini, Y. Cohen, L. Cressiot, F. Cymbalista, M. Didier, F. Duperon, C. Duran, J. Darmon, E. Fresnel, T. Fouque, O. Freynet, T. Gille, C. Gilles, S. Greffe, P. Hammel, F. Jeny, W. Khamis, F Khort, V. Levy, M. Lupo, A. Navid, S. Peres, C. Planes, M. Patout, M. Pepin, C. Rotenberg, D. Roche-Lebrec, S. Saadi, Y. Uzunhan and D. Valeyre.

Conflict of interest: L. Sesé reports personal fees and non-financial support from Roche/Genentech (consultant and congress), and non-financial support from Boehringer Ingelheim (congress), outside the submitted work. Y. Nguyen has nothing to disclose. E. Giroux Leprieur reports grants, personal fees and non-financial support from AstraZeneca, Bristol-Myers-Squibb and Roche, personal fees and non-financial support from Boehringer Ingelheim, MSD and Novartis, and non-financial support from Takeda, outside the submitted work. I. Annesi-Maesano has nothing to disclose. C. Cavalin has nothing to disclose. J. Goupil de Bouillé has nothing to disclose. L. Demestier has nothing to disclose. R. Dhote has nothing to disclose. Y. Tandjaoui-Lambiotte has nothing to disclose. A. Bauvois has nothing to disclose. M. Pépin has nothing to disclose. S. Curac has nothing to disclose. S. Beaune has nothing to disclose. B. Duchemann reports non-financial support from Roche, Oxyvie, Pfizer and AstraZeneca, and personal fees from MSD, outside the submitted work. H. Nunes reports grants and personal fees from Roche/Genentech (consultant and research support fees) and Boehringer Ingelheim (consultant and research support fees), personal fees from Galapagos (expert for clinical endpoint committee), other from Sanofi (investigator of clinical trial), Gilead (investigator of clinical trial), Novartis (investigator of clinical trial) and Galecto Biotech AB (investigator of clinical trial), during the conduct of the study; personal fees from Actelion Pharmaceuticals (board expert for clinical trial), outside the submitted work.

\section{References}

1 Yancy CW. COVID-19 and African Americans. JAMA 2020; 323: 1891-1892.

2 Chowkwanyun M, Reed AL. Racial health disparities and Covid-19 - caution and context. N Engl J Med 2020; 383: 201-203.

3 Insee. Evolution of Deaths Since 1 March - Number of Daily Deaths. www.insee.fr/en/statistiques/4493806? sommaire $=4493845 \#$ consulter-sommaire Date last accessed: 20 May 2020.

4 Insee. Comparateur de territoire. www.insee.fr/fr/statistiques/1405599?geo=DEP-92+DEP-93+DEP-75+DEP-94 +UU2010-00851 Date last accessed: 20 May 2020.

5 Insee. Comparateur de territoire - Département des Hauts-de-Seine. www.insee.fr/fr/statistiques/1405599? geo=DEP-92 Date last accessed: 1 Jun 2020

6 Le Projet Régional de Santé 2018-2022. www.iledefrance.ars.sante.fr/le-projet-regional-de-sante-2018-2022 Date last accessed: 31 Aug 2020.

7 Sass C, Guéguen R, Moulin JJ, et al. [Comparison of the individual deprivation index of the French Health Examination Centres and the administrative definition of deprivation]. Sante Publique 2006; 18: 513-522.

8 Zu ZY, Jiang MD, Xu PP, et al. Coronavirus disease 2019 (COVID-19): a perspective from China. Radiology 2020; 296: 200490.

9 World Health Organization. Clinical Management of Severe Acute Respiratory Infection (SARI) when COVID-19 Disease is Suspected: Interim Guidance, 13 March 2020. https://apps.who.int/iris/handle/10665/331446?searchresult=true\&query=10665\%2F331446\&scope=\&rpp=10\&sort_by=score\&order=desc Date last accessed: 1 Jun 2020. Date last updated: 13 Mar 2020.

10 Docherty AB, Harrison EM, Green CA, et al. Features of 20133 UK patients in hospital with Covid-19 using the ISARIC WHO Clinical Characterisation Protocol: prospective observational cohort study. BMJ 2020; 369: m1985.

11 Simonnet A, Chetboun M, Poissy J, et al. High prevalence of obesity in severe acute respiratory syndrome coronavirus-2 (SARS-CoV-2) requiring invasive mechanical ventilation. Obesity 2020; 28: 1195-1199.

12 Yang J, Zheng Y, Gou X, et al. Prevalence of comorbidities and its effects in patients infected with SARS-CoV-2: a systematic review and meta-analysis. Int J Infect Dis 2020; 94: 91-95.

13 Chetty R, Stepner M, Abraham S, et al. The association between income and life expectancy in the United States, 2001-2014. JAMA 2016; 315: 1750-1766.

14 von dem Knesebeck O, Verde PE, Dragano N. Education and health in 22 European countries. Soc Sci Med 2006; 63: 1344-1351.

15 Insee. Life expectancy by Standard of Living: in Men, 13 Years of Difference Between the Most Affluent and the Most Modest - Insee Première - 1687. www.insee.fr/en/statistiques/3533552 Date last accessed: 4 May 2020.

16 Labbe E, Blanquet M, Gerbaud L, et al. A new reliable index to measure individual deprivation: the EPICES score. Eur J Public Health 2015; 25: 604-609. 